\section{Surgeons seek go-ahead to perform first face transplant}

\section{Erika Check, Washington}

A surgical team pushing for permission to do the world's first face transplant said last week that the potential benefits of the procedure outweigh the social and ethical problems that it raises.

Ethical bodies in France and Britain have already denied permission for surgeons in those countries to perform face transplants, which would probably be used to treat people whose features had been severely disfigured in fires or other accidents.

But now a team of surgeons, psychologists and sociologists at the University of Louisville in Kentucky and Utrecht University in the Netherlands says that it can address the concerns raised by ethical boards elsewhere. In an article in the American Journal of Bioethics on 17 September, the team argues that science is far enough advanced to diminish the risks posed by the operation, pointing to advances in immunosuppressive medication and in plastic surgery on complicated organs such as hands.

The team has already submitted a facetransplant proposal to an ethics review body in the Netherlands, and it plans to submit one soon to a review board in the United States. John Barker of the University of Louisville, who leads the team, says he hopes to hear whether the Dutch proposal has been accepted by the end of this week.

In the article, the team admits that there are many uncertainties about face transplants. For instance, the face is intimately linked with a person's identity, and it is difficult to know how a face-transplant recipient will adjust to his or her new appearance. And the family of the patient who donates the face might take exception to the procedure. But proponents say that there is a limit to what can be done to address these issues, which cannot be resolved through further experiments on animals or lab tests. "There arrives a point in time when the procedure should simply be done," the team writes. "We submit that that time is now."

However, ethicists and specialists asked to review the proposal have said that it is premature. In responses published with the article in the bioethics journal, ethicists point out that the best success rate for large organ transplants is about $84 \%$. This means that one in five face transplants could fail, leading to the loss of the transplanted face. Failed transplants would leave vulnerable people much worse off, some argue, because the operation would have removed whatever facial tissue the patient had before the procedure.

Critics also contend that hand transplants, which the Louisville team has performed,

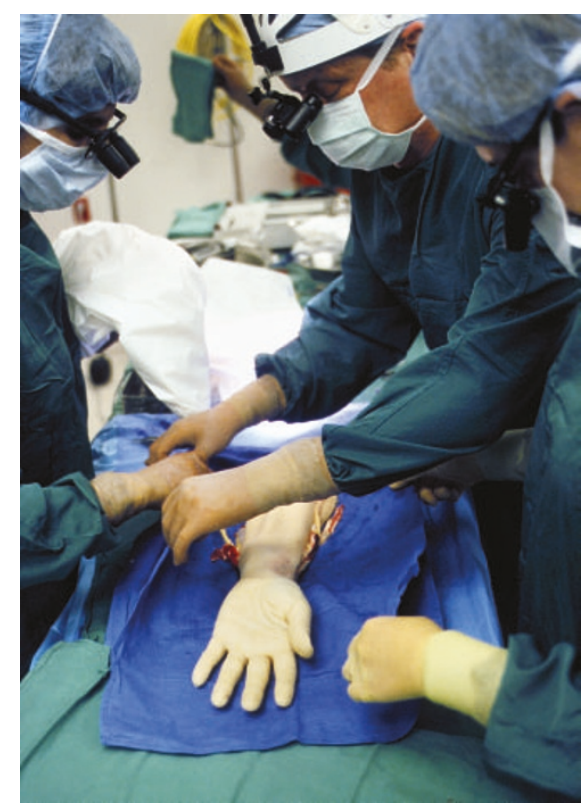

Helping hand: experiments with other complex organs point the way to full facial transplants.

have not been successful enough to justify further similar experiments. And they point out that immunosuppressive drugs given to facetransplant recipients have toxic side-effects, which could endanger the recipient's life.

"I think there hasn't been enough background research to prove that it will work, and they haven't figured out what to do if it doesn't work," says medical ethicist Arthur Caplan, director of the Center for Bioethics at the University of Pennsylvania in Philadelphia.

The transplant team counters that the hand transplants have shown how successful large organ transplants can be, because only two of 24 hands transplanted around the world have been rejected. However, this sample is small and the grafts have all been performed relatively recently. The team has also conducted numerous preparatory experiments, such as face transplants from one cadaver to another.

Barker says that careful patient selection would address the concerns about a failed transplant. The team would try to select a recipient recovering from a recent disfiguring event instead of one who has already gone through years of reconstructive surgery. That way, if the graft failed, the patient would have lost little. Careful preparation could also help the recipient deal with the inevitable media storm that would follow such a transplant, the Louisville team says.

Critics counter that the risk of the procedure is just too high. Any day now, the Netherlands review panel is expected to decide who it thinks is right.

\section{US health agency opens landmark clinical centre}

Helen Pearson

Clinical research at the National Institutes of Health (NIH) was due to receive a major boost this week with the official opening of a 242-bed, $\$ 540$-million centre at the agency's main campus in Bethesda, Maryland.

A ribbon-cutting ceremony on 22 September launched what is said to be the largest centre of its kind in the world. It is named the Mark O. Hatfield Clinical Research Center, after an Oregon senator who strongly supported the NIH.

The centre will form the mainstay of the NIH's intramural clinical research programme at a time when the institute's director, Elias Zerhouni, is striving to improve links between laboratory and clinical research. "There will be a lot of people watching - and hopefully we won't disappoint," says the centre's director, immunologist John Gallin.

Laboratories and patient wards sit side by side in the new building and most are equipped for either function, allowing space to be transferred seamlessly from one purpose to the other.

The centre also boasts special facilities, such as a 12-bed unit devoted to clinical studies of obesity. To take account of its residents' unusual size, the unit includes an enlarged magnetic resonance imaging scanner, widened doorways, reinforced toilets and vending machines that log the calorific value of patients' selections. One of the issues researchers plan to study is whether obese people's physiology and brain activity change after stomach-reducing surgery.

But, like other clinical research programmes in the United States, the centre faces a challenge in attracting staff with appropriate experience, as most physicians are encouraged to pursue lucrative work on patients rather than research. The centre is developing a variety of measures to entice researchers, including a computer system to cut the paperwork surrounding clinical trials.

The centre will also focus effort on areas that are sometimes ignored by other medical institutions, such as research into rare diseases, says the president of Boston's Dana-Farber Cancer Institute, Ed Benz, who chaired a panel earlier this year on the future of NIH intramural clinical research. 